Int. J. Electrochem. Sci., 12 (2017) 10471 - 10483

International Journal of

ELECTROCHEMICAL

SCIENCE

www.electrochemsci.org

\title{
High-Performance N-doped Bifunctional Carbon Electrocatalysts Derived from Polymer Waste for Oxygen Reduction and Evolution Reaction
}

\author{
Jinjin Xuan, Ziwu Liu* \\ Low Carbon Energy Institute and School of Chemical Engineering, China University of Mining \& \\ Technology, Xuzhou 221008, Jiangsu, China \\ *E-mail: $\underline{\text { lzwmsy@cumt.edu.cn }}$
}

doi: $10.20964 / 2017.11 .42$

Received: 12 June 2017 / Accepted: 4 September 2017 / Published: 12 October 2017

\begin{abstract}
Developing novel bifunctional heteroatom-doped carbon electrocatalysts for the oxygen reduction reaction (ORR) and oxygen evolution reaction (OER) is vital for the development of fuel cells, metalair batteries and water oxidation systems. Herein, a nitrogen $(\mathrm{N})$-containing polymer waste was collected and used to synthesize N-doped bifunctional carbon electrocatalysts (N-BCEs). The results indicated that the N-containing polymer waste from a living environment can be converted to N-BCEs easily. In addition, the surface areas, pore structures and $\mathrm{N}$ doping contents of N-BCEs were further optimized by cyanoguanidine. Most importantly, the electrochemical tests demonstrated that the asprepared N-BCEs exhibited comparable ORR and OER activities to the commercial noble-metal Pt-C and $\mathrm{IrO}_{2}$ electrocatalysts in both acidic and alkaline media, indicating that environmentally-unfriendly heteroatom-containing polymer wastes can be utilized to synthesize advanced heteroatom-doped BCEs for ORR and OER in future fuel cells, metal-air batteries and water oxidation.
\end{abstract}

Keywords: N-containing polymer wastes; bifunctional electrocatalysts; oxygen reduction reaction; oxygen evolution reaction; electrocatalysis

\section{$\underline{\text { FULL TEXT }}$}

(C) 2017 The Authors. Published by ESG (www.electrochemsci.org). This article is an open access article distributed under the terms and conditions of the Creative Commons Attribution license (http://creativecommons.org/licenses/by/4.0/). 